Opinion

\section{Hypothesis about pathogenic action of Sars-COV-2}

\author{
Marasco Daniela, Del Prete Salvatore ${ }^{1 \star}$ and Sabetta Rosalaura² \\ 'Service Biotech s.r.I., Napoli, Via Monte di Dio 80, 80132, Italy \\ ${ }^{2}$ Department of Mental Health and Physics and Preventive Medicine, University of Campania Luigi \\ Vanvitelli, Naples, Italy
}

\section{Abstract}

The Hypothesis born on a simple clinical data noted by some Chinese Reserchers during the starting point of epidemic began in the dicember of the 2019, for the novel member of human coronavirus, officially named as SARS-CoV-2 (severe acute respiratory syndrome coronavirus 2) by International Committee on Taxonomy of Viruses (ICTV) is a new strain of RNA viruses that has not been previously identified in humans [1]. Sars-COV and SARS CoV-2 have some clinical differences. First: The Sars, severe acute respiratory sindrome induce a respiratory disease in immunocompetent hosts, although can cause severe infections in infant, young children and elderly individuals; Sars-CoV-2 induce a middle infection into the young children but the mortality is more high in to the adult population. We made a macthing with balst $\mathrm{p}$ of these sequences, Sars COV-2, taken on GENEBANK with H1N1 neuraminidase and the not structural protein NS1 and NS2 an interferon antagonist that may also stimulate proinflammatory cytokines in infected cells We can speculate that the mutation is occurred on accessories protein making a different virulence action between the two species Sars Cov and Sars Cov-2, same action we have founded in the $\mathrm{H}_{1} \mathrm{~N}_{1}$ viral pandemic of the 2019 .

\section{More Information}

*Address for Correspondence: Del Prete Salvatore, Service Biotech s.r.l., Napoli, Via Monte di Dio 80, 80132, Italy, Tel: +08119134076; Email: saldelp@gmail.com

Submitted: 06 March 2020 Approved: 26 March 2020 Published: 27 March 2020

How to cite this article: Marasco D, Del Prete S, Sabetta R. Hypothesis about pathogenic action of Sars-COV-2. Int J Clin Virol. 2020; 4: 021-022.

DOI: 10.29328/journal.ijcv.1001009

ORCiD: orcid.org/0000-0001-6004-7781

Copyright: (C) 2020 Marasco D, et al. This is an open access article distributed under the Creative Commons Attribution License, which permits unrestricted use, distribution, and reproduction in any medium, provided the original work is properly cited.

Keywords: Sars-COV-2; Hotspot mutation; $\mathrm{H}_{1} \mathrm{~N}_{1}$

Check for updates

OPEN ACCESS

\section{Introduction}

The Hypothesis born on a simple clinical data noted by some Chinese Reserchers during the starting point of epidemic began in the dicember of the 2019, for the novel member of human coronavirus, officially named as SARS-CoV-2 (severe acute respiratory syndrome coronavirus 2) by International Committee on Taxonomy of Viruses (ICTV) is a new strain of RNA viruses that has not been previously identified in humans [1]. Sars-COV and SARS CoV-2 have some clinical differences. First: The Sars ,severe acute respiratory sindrome induce a respiratory disease in immunocompetent hosts, although can cause severe infections in infant, young children and elderly individuals; Sars-CoV-2 induce a middle infection into the young children but the mortality is more high in to the adult population: this way of infection it isn't a classic way because the child doesn't have a strong immunitary response, therefore this atipical response remember us the infection of Spanish influenza just known as pandemic spanish influenza; it had an high score of mortality between the 1918 and the 1920, killing millions of persons all around the world. In the 2009 we had another pandemic influenza from $\mathrm{H}_{1} \mathrm{~N}_{1}$ virus and it was characterized by at similar mortality score. At this regarding the risk factors for severe disease, obesity was an important predisposing factor, in addition to extremes of age, pregnancy, and underlying medical illness [2]. In patients with severe disease, viral clearance was delayed, with a persistent elevation of pro-inflammatory cytokines and associated multiorgan damage despite antiviral therapy [2]. Additionally, a lower serum IgG2 level appeared to be associated with disease severity, especially in pregnant patients. Severe disease and lung pathology were associated with immune complex deposition. The second element of this pathogenic coronaviruses SARS-CoV-2 is a cytochine storm*6 [3]. It was demonstrated that SARS-COV and SARS-CoV-2 are similiar, so we have supposed that both these viruses can doing matching in them hotspot mutation. In the lecterature these hot spots are orf8 and orf3 [4]. We, in our hypothesis, considered also another hot spot; Orf $1 \mathrm{ab}$ as an interest point [5]. We made a macthing with balst $p$ of these sequences, Sars COV-2, taken on GENBANK with $\mathrm{H}_{1} \mathrm{~N}_{1}$ neuraminidase and the not structural protein NS1 and NS2 an interferon antagonist that may also stimulate proinflammatory cytokines in infected cells [6,7], (Death is aborted by blockade of interferon-1 (IFN-1) signaling or deletion of CD8 T cells).

\section{Materials and methods}

We used to identify, a possible genomic correspondence between $\mathrm{H}_{1} \mathrm{~N}_{1}$ and Sars COV-2, Gene Bank for identification of amminoacids sequence of Orf $1 \mathrm{ab}$, Orf $3 \mathrm{a}$ (hot spot mutation 
for Sars COV-2), Neuraminidase segment and NS1/NS2 (factor of $\mathrm{H}_{1} \mathrm{~N}_{1}$ virulence) and BLASTp ncbi program for matching these sequences. We match before Orf 3 a with neuraminidase amminoacids sequence then Orf $1 \mathrm{ab}$ with NS1/NS2 aminoacids sequence.

Results are for Orf $3 \mathrm{a}$ and neuraminidase of $\mathrm{H}_{1} \mathrm{~N}_{1}$ : e-value 0.23 ; Query cover of $22 \%$ and percent identity of $22,22 \%$, but the most important data is in the range 2 where we find an identities of $100 \%$ with positivity of $100 \%$ for sequence 311 315 of neuraminidase $\mathrm{H}_{1} \mathrm{~N}_{1}$ the sequence expressed in both is: DYQIG. The results of matching between Orf $1 \mathrm{ab}$ of SarsCOV-2 and NS1/NS2 of $\mathrm{H}_{1} \mathrm{~N}_{1}$ present an e-value of 1.2 (little bit significance) but with an Query cover of $51 \%$ and a percent identity of $40 \%$. Even if the e-value is little bit high we have a significance match score and query cover; that purpose an hypothesis of mutation of the Sars-COV-2 in sense of $\mathrm{H}_{1} \mathrm{~N}_{1}$. At last we made another analysis matching between ORF8a of Sars-COV-2 and neuraminidase of $\mathrm{H}_{1} \mathrm{~N}_{1}$; these sequence matching have expressed an evalue of 2.2 with a query cover of $15 \%$ and percent identity of $23,3 \%$, in this case we can say that we not have a significative correspondence between these sequences not only for the e-value to much high but also for the query cover that is not too significance. To support our theory we have made some control test matching between Sars-COV Orf $1 \mathrm{ab}$ and Orf $1 \mathrm{ab}$ Sars-COV-2 that present a query cover of $100 \%$ e-value 0.0 and identity percent of $86,16 \%$, so we speculate that in Orf 1 ab Sars COV have lose some amminoacids passing to COV-2 (our control). Then we matching, for control analisys too Orf 3 of Sars COV and Orf $3 a$ of Sars COV-2 with a query cover of $64 \%$ e-value $3 e-154$ and an identity percent of $72 \%$; we match also neuraminidase with Orf3 Sars COV with a query $4 \%$, e-value 0,74 and an identity percent of $62,5 \%$.

We can speculate that the mutation is occurred on accessories protein making a different virulence action between the two species Sars Cov and Sars Cov-2 infact in the licterature we know that the Sras Cov has like target children and seniors; this aspect in Sars COV-2 is less present; Furthermore Sars COV-2 presents a citokine storm like immune reaction at this virus. This fact can suggest a direct attack on the immune system or a specific defense mechanism of the virus. The same action we have founded in the $\mathrm{H}_{1} \mathrm{~N}_{1}$ viral pandemic of the 2019; the citokine storm is the principal cause of the high mortality and morbidity of this virus that attack respiratory ways.

\section{Results}

\section{Table 1}

ORF 3a Sars COV-2 match $\mathrm{H}_{1} \mathrm{~N}_{1}$ neurominidase

Range 2: 183 to 187

Score:15.4 bits(28), Expect: 2.4,

Method: Compositional matrix adjust.,

Identities: 5/5 (100\%), Positives: 5/5 (100\%), Gaps:0/5(0\%)

Query 311 DYQIG 315 Sbjct

183 DYQIG 187

We can see a strong matching between Query sequence $\mathrm{H}_{1} \mathrm{~N}_{1}$ neurominidase and Sars COV2 Orf $3 a$.

\section{Discussion and conclusion}

Our Hypothesis is that Sars COV-2 could near at H1N1 for two reasons; first one the action of the virus on guest immune system and the second one the strong similarity in the matching supposed. If this correspondence could be true, we can considerate the Orf3a and Orf $1 \mathrm{ab}$ as target of some drugs already useful against neurominidase and Ns1/ NS2 of $\mathrm{H}_{1} \mathrm{~N}_{1}$. Our Hypothesis is sustained by the new Italian datas of infection; the patient are treated with cortisone and tocilizumab that intervene on cytochine storm.

\section{Declaration}

\section{Ethical approval}

All procedures performed in studies involving human participants were in accordance with the ethical standards of the institutional national research committee and with the 1964 Helsinki declaration and its later amendments or comparable ethical standards.

\section{References}

1. Zhang JJ, Dong $X$, Cao YY, Yuan YD, Yang YB, et al. Clinical characteristics of 140 patients infected by SARS-CoV-2 in Wuhan, China. EAACI. 2020.

2. Cheng VC, To KK, Tse H, Hung IF, Yuen KY. Two years after pandemic influenza $A / 2009 / \mathrm{H} 1 \mathrm{~N} 1$ : what have we learned? Clin Microbiol Rev. 2012; 25: 223-263.

PubMed: https://www.ncbi.nlm.nih.gov/pubmed/22491771

3. Cui J, Li F, Shi ZL. Origin and evolution of pathogenic coronaviruses. Nat Rev Microbiol. 2019; 17: 181-192.

PubMed: https://www.ncbi.nlm.nih.gov/pubmed/30531947

4. Oldstone MB. Lessons learned and concepts formed from study of the pathogenesis of the two negative-strand viruses lymphocytic choriomeningitis and influenza. Proc Natl Acad Sci USA. 2013; 110: 4180-4183.

PubMed: https://www.ncbi.nlm.nih.gov/pubmed/23341590

5. Xia S, Zhu Y, Liu M, Lan Q, Xu W, et al. Fusion mechanism of 2019-nCoV and fusion inhibitors targeting HR1 domain in spike protein. Cell Mol Immunol. 2020.

PubMed: https://www.ncbi.nlm.nih.gov/pubmed/32047258

6. Oldstone MBA, Ware BC, Horton LE, Welch MJ, Aiolfi R, et al. Lymphocytic choriomeningitis virus Clone 13 infection causes either persistence or acute death dependent on IFN-1, cytotoxic T lymphocytes (CTLs), and host genetics. Proc Natl Acad Sci USA. 2018; 115: E7814-E7823. PubMed: https://www.ncbi.nlm.nih.gov/pubmed/30061383

7. Xu K, Cai H, Shen Y, Ni Q, Chen Y, et al. Management of corona virus disease-19 (COVID-19): the Zhejiang experience. Zhejiang Da Xue Xue Bao Yi Xue Ban. 2020; 49: 0.

PubMed: https://www.ncbi.nlm.nih.gov/pubmed/32096367 